\title{
Gas Holdup and Gas-Liquid Mass Transfer Investigations in an Oscillatory Baffled Column
}

\author{
Taslim and Mohd Sobri Takriff* \\ Department of Chemical and Process Engineering, \\ Universiti Kebangsaan Malaysia, \\ 43600 Bangi, Selangor, Malaysia
}

\begin{abstract}
Gas holdup and gas-liquid mass transfer were investigated in a vertical baffled column. Pure carbon dioxide $\left(\mathrm{CO}_{2}\right)$ was used as the dispersed phase and tap water was used as the continuous phase. Gas holdup and mass transfer rate of $\mathrm{CO}_{2}$ were measured under semi-batch condition, while the liquid phase was measured in batch mode. Gas holdup was estimated as the volume fraction of the gas in the two-phase mixture in the column. Mass transfer was expressed in terms of the liquid-side volumetric mass transfer coefficient $\left(k_{L} a\right)$. The effects of oscillation frequency, oscillation amplitude and gas flow rate on gas holdup and mass transfer were also determined. The results showed that a significant increase in gas holdup and mass transfer could be achieved in an oscillatory baffled column compared to a bubble column. Gas holdup and mass transfer were correlated as a function of power density and superficial gas velocity.
\end{abstract}

Keywords: gas holdup, mass transfer coefficient, power density, superficial gas velocity

\section{INTRODUCTION}

Contact between gas phase and liquid phase plays a key role in many chemical processes, especially when mass transfer between the phases is the rate-controlling step for the overall process. Gas holdup and mass transfer coefficients are important parameters in the charaterization and design of gas-liquid contactors, and oscillatory baffled columns are no exceptions. Oscillatory baffled columns have been reported in numerous publications as a promising method to improve mixing in columns (Mackley, $1987 \&$ 1991). The radial velocity component is comparable to the axial velocity component, giving enhance mixing in both directions (Brunold et. al., 1989; Dickens et al., 1989). As a result, heat and mass transfer are significantly improved (Mackey, 1990; Hewgill et. al., 1993).
The fluid mechanics within a baffled column is controlled by the geometrical configuration of the baffles and two dimensionless parameters. The first parameter is the oscillatory Reynolds number, $\mathrm{Re}_{\text {。 }}$, which describes the intensity of mixing applied to the column.

$$
\operatorname{Re}_{0}=\frac{\rho \omega x_{0} D}{\mu}
$$

The second parameter is the Strouhal number, St, which represents a ratio of column diameter to stroke length, measuring effective eddy propagation (Ni \& Gough, 1997).

$$
\mathrm{St}=\frac{\mathrm{D}}{4 \pi \mathrm{x}_{\mathrm{O}}}
$$

Brunold et al., (1989) indicated that the baffle spacing of order 1.5 column diameter and 
the constriction of ratio to about $60 \%$ was optimal to achieve good mixing in oscillatory condition. Mackay et al., (1991) indicated that the wall baffle (orifice type) gives the impression of a more chaotic flow compared to a central baffle. This means that overall mixing appears to be greater for orifice baffles than central baffles.

Gas holdup and mass transfer enhancement via oscillatory baffled columns received some attention in recent years (Baird et. al., 1996; Hewgill et. al., 1993). However, these studies were concentrated either on gas holdup or mass transfer only. The objectives of this paper were to investigate gas holdup and gas-liquid mass transfer in an oscillatory baffled column and propose a correlation for gas holdup and mass transfer.

\section{MATERIALS AND METHODS}

A schematic diagram of the experimental apparatus is shown in Figure 1. The experiments were conducted in a vertical Perspex column with a height of $1200 \mathrm{~mm}$ and a diameter of $94 \mathrm{~mm}$. Its top is open to the atmosphere. Seven orifice type baffle plates with a spacing of $141 \mathrm{~mm}$ in between plates supported by two stainless steel rods with a $6 \mathrm{~mm}$ diameter were installed in the column. The diameter of the baffle is $94 \mathrm{~mm}$ and each baffle has a central hole with a $50 \mathrm{~mm}$ diameter. A pneumatically-driven piston mounted at the bottom of the column was used to oscillate the liquid phase. Oscillation frequency can be varied by adjusting the air pressure of the compressor of the pneumatic unit to provide frequencies ranging from 0.5 to $2.0 \mathrm{~Hz}$. Various oscillation amplitudes can be obtained by adjusting the distance between the two sensors at the pneumatic cylinder to give amplitudes that range from 10 to $40 \mathrm{~mm}$. A summary of the range of experimental conditions used in this work is presented in Tabel 1.

The column was filled with tap water at room temperature and initial liquid height was measured. Compressed $\mathrm{CO}_{2}$ from a cylinder was fed into the column via a nozzle with a $3 \mathrm{~mm}$ diameter and final liquid height was measured. These measurements were made after a steady state was achieved. Volume occupied by the gas phase was estimated from the final liquid volume

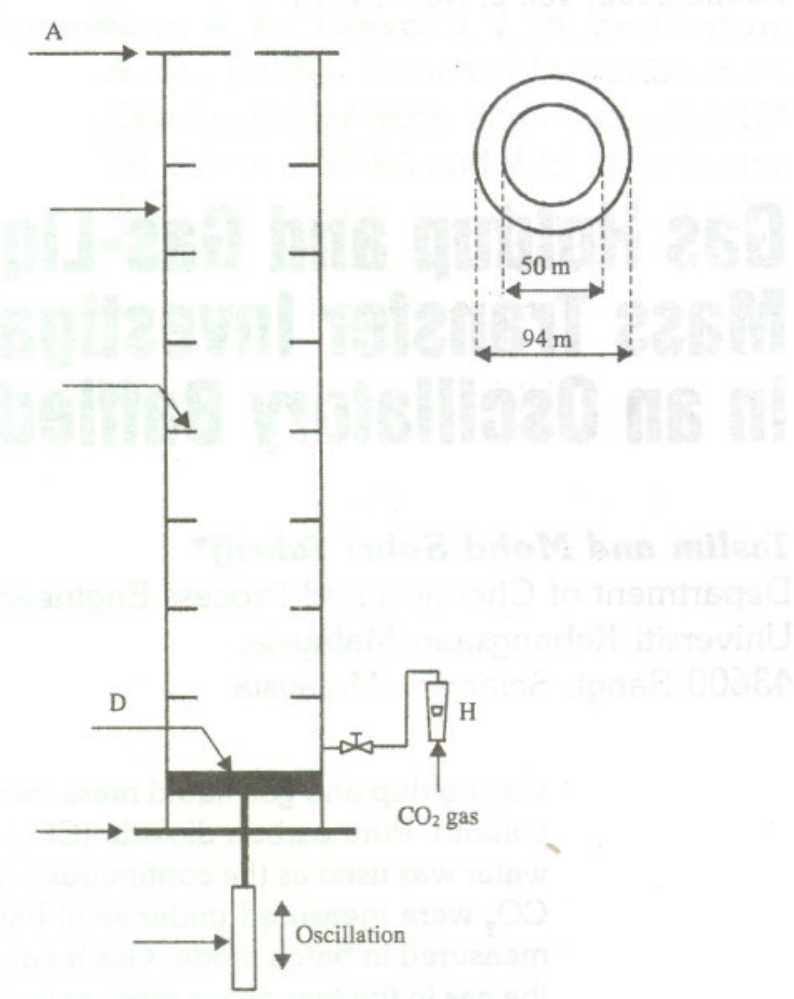

A. Top plate, B. Column, C. Orifice baffle plate, D. Piston E. Metal table, F. Pneumatic unit, G. One way valve, H. Rotameter

Figure 1. Schematic diagram of experimental apparatus

less the initial liquid volume. The gas holdup $\left(e_{\mathrm{g}}\right)$ was determined from the following equation:

$e_{g}=V_{g} /\left(V_{1}+V_{g}\right)$

Table 1. Details of experimental conditions

\begin{tabular}{|l|c|}
\hline \multicolumn{1}{|c|}{ Details } & Range \\
\hline Oscillation frequency, $\mathrm{f}$ & $0.5-2.0 \mathrm{~Hz}$ \\
Oscillation amplitude, $\mathrm{x}_{\mathrm{o}}$ & $10-40 \mathrm{~mm}$ \\
Superficial gas velocity, $\mathrm{U}_{\mathrm{g}}$ & $0.026-0.072 \mathrm{~m} / \mathrm{s}$ \\
Inside column diameter, $\mathrm{D}$ & $94 \mathrm{~mm}$ \\
Column height, $\mathrm{H}$ & $1200 \mathrm{~mm}$ \\
Orifice diameter, $\mathrm{D}_{0}$ & $50 \mathrm{~mm}$ \\
Baffle spacing & $141 \mathrm{~mm}$ \\
Number of baffles, $\mathrm{N}$ & 7 \\
Thickness of baffles & $3 \mathrm{~mm}$ \\
Diameter of supporting rods & $6 \mathrm{~mm}$ \\
\hline
\end{tabular}


Rate of $\mathrm{CO}_{2}$ transfer from the $\mathrm{CO}_{2}$ bubble to the liquid phase can be described using the following relationship, assuming there is complete mixing of the liquid phase.

$$
\mathrm{dC} / \mathrm{dt}=\mathrm{k}_{\mathrm{L}} \mathrm{a}\left(\mathrm{C}^{*}-\mathrm{C}\right)
$$

The concentration of dissolved $\mathrm{CO}_{2}$ in the continuous phase was measured by titration. Integrating Equation (4) gives:

$$
\ln \left(C^{*}-C\right)=-k_{L} a t+\text { constant }
$$

The $\mathrm{k}_{\mathrm{L}}$ a can be directly determined by plotting $\ln \left(\mathrm{C}^{*}-\mathrm{C}\right)$ against $\mathrm{t}$. The $\mathrm{k}_{\mathrm{L}} \mathrm{a}$ is the slope of the straight line obtained.

In the case of a bubble column contactor, mixing is induced pneumatically. The total specific power density $(\mathrm{P} / \mathrm{V})$ can be related to the dispersion into the gas liquid mixing according to the following equation (Bouaifi et. al., 2001):

$$
(\mathrm{P} / \mathrm{V})_{\mathrm{BC}}=\rho_{1} \mathrm{~g} \mathrm{U}_{\mathrm{g}}
$$

In the oscillatory baffled column, estimation of power density was closely related to both oscillation frequency and amplitude and was derived from the work of Jealous and Johnson (1955). This method calculates pressure drop across an orifice plate and integrates the work done over a complete cycle. This gives a timeaveraged power density as follows (Baird and Stonestreet, 1995):

$$
(\mathrm{P} / \mathrm{V})_{\mathrm{OBC}}=\frac{2 \rho \mathrm{N}}{3 \pi \mathrm{C}_{\mathrm{D}}^{2}}\left(\frac{1-\alpha}{\alpha^{2}}\right) \mathrm{x}_{\mathrm{O}}^{3} \omega^{3}
$$

\section{RESULTS AND DISCUSSION}

\section{Gas holdup}

Gas holdup experiments in the absence of baffles and liquid oscillation were first carried out to establish a basis for comparison with gas holdup studied under oscillatory condition. The effects of liquid oscillation in the absence of baffles and the presence of baffles without liquid oscillation were also studied. Gas holdup was estimated from raw experimental data using Equation (3). Gas holdup was found to increase with gas velocity. The presence of liquid oscillation and the absence of baffles have negligible effects on gas holdup. On the other hand, the presence of baffles lowers gas holdup. The observation reflected restriction of bubble dispersion, forcing bubbles to flow only through the centre of the column. This results to lower gas holdup.

The dependence of gas holdup on superficial gas velocity for bubble columns can be expressed as:

$$
\varepsilon_{\mathrm{g}}=\mathrm{a}_{1} \mathrm{U}_{\mathrm{g}}^{\mathrm{b}}
$$

The experimental data were fitted with superficial gas velocity using Equation (8) to give $a_{1}=1.12$ and $b=0.9$, which are consistent with the values obtained from the related literature (Shah et. al., 1982). When orifice baffles were inserted into the column without liquid oscillation, the value of $a_{1}$ and $b$ became 0.85 and 0.88 , respectively.

The dependency of gas holdup versus power density for the bubble column can be written as (Bouaifi et. al., 2001):

$$
\varepsilon_{\mathrm{g}}=\mathrm{a}_{2}(\mathrm{P} / \mathrm{V})_{\mathrm{BC}}^{\mathrm{c}}
$$

Experimental values of $\mathrm{a}_{2}$ and $\mathrm{c}$ in this study were 0.0003 and 0.89 , respectively. If there were baffles in the column, the values of $\mathrm{a}_{2}$ and $\mathrm{c}$ became 0.0002 and 0.87 , respectively.

The combined effects of liquid oscillation and the presence of baffles on gas holdup were investigated at difference oscillatory conditions. Gas holdup was plotted against oscillation velocity which is the product of oscillation amplitude and frequency $\left(\mathrm{x}_{0} \mathrm{f}\right)$, as shown in Figure 2 . It can be seen that gas holdup increases with gas velocity for a given $x_{0}$. Oscillation velocity has minimal effect on gas holdup when $x_{0} f$ is less than $20 \mathrm{~mm} / \mathrm{s}$ for a given gas velocity. Above this value, oscillation velocity has a big effect on gas holdup. The data trends for this work and a previous work (Baird et. al., 1996) are qualitatively similar.

Gas holdup increased in the presence of liquid oscillation and baffle plates. Generally, increase in gas flow rate causes an increase in the number of bubbles. Under oscillatory 


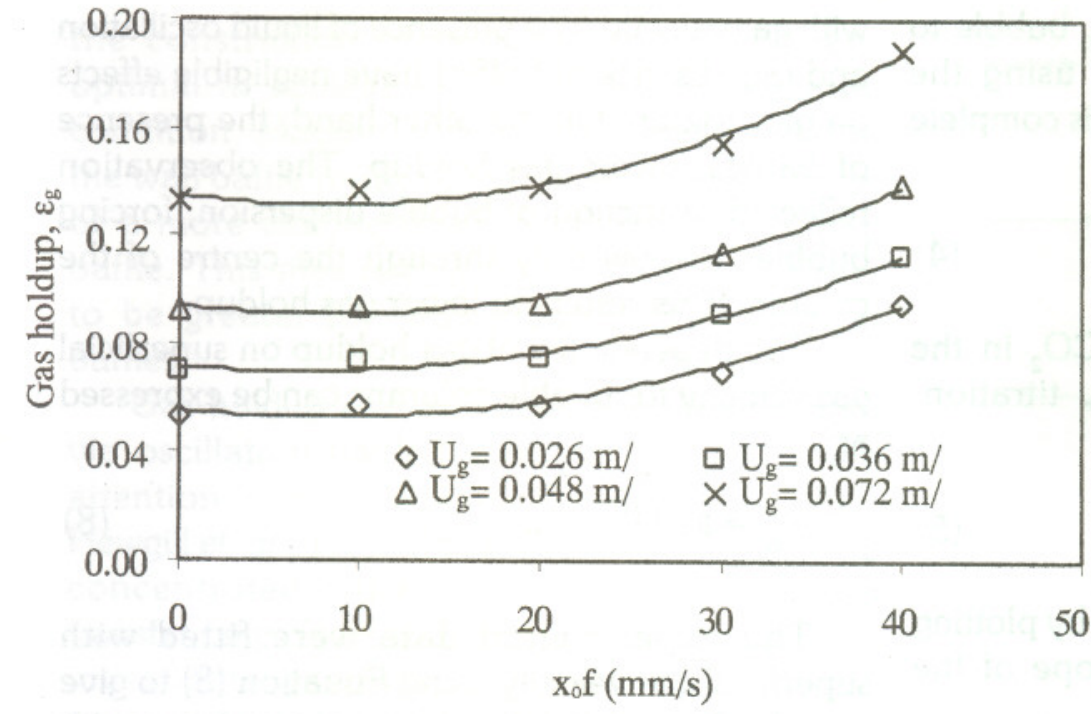

Figure 2. The effect of oscillation velocity (product of oscillation amplitude and frequency) on gas holdup
Fitting the present data with the above correlation yielded $\mathrm{a}_{3}=0.79, \mathrm{~d}=0.1$, and $e=0.79$. The experimental data and the correlation were plotted together in Figure 3.

\section{Mass transfer}

The volumetric mass transfer coefficient, $\mathrm{k}_{\mathrm{L}} \mathrm{a}$, was obtained from experimental data using Equation (5) and the plot for this equation is shown in Figure 4. The values of $k_{L} a$ are the slope of the straight lines in Figure 4 and condition, small bubbles were formed due to the interaction of fluid oscillation and the baffle edges. Smaller bubbles lowered rising velocity, thus remaining longer in the column. Besides the formation of more smaller bubbles, gas flow is subjected to higher drag through plate holes. As a result, a significant increase in gas hold up is observed.

The gas holdup is plotted against power density calculated using Equation (7) in Figure 3 . It can be seen that $e_{\mathrm{g}}$ increases with power density. This figure shows that the gas holdup significantly increases at a lower range of power density reaching up to about $500 \mathrm{~W} /$ $\mathrm{m}^{3}$. Beyond this value, gas holdup increases in a linear fashion. Higher power inputs per unit volume led to better mixing intensity and consequently a higher $e_{g}$ was obtained. In the oscillatory baffled column, correlation of gas holdup as a function of power density and superficial gas velocity can be written as:

$\varepsilon_{\mathrm{g}}=\mathrm{a}_{3}(\mathrm{P} / \mathrm{V})_{\mathrm{OBC}}^{\mathrm{d}} \mathrm{U}_{\mathrm{g}}^{\mathrm{e}}$ given in Table 2 . The value of $\mathrm{k}_{\mathrm{L}}$ a in an oscillatory baffled column ( $\mathrm{f}=1 \mathrm{~Hz}, \mathrm{x}_{0}=4 \mathrm{~cm}$ ) is approximately three times greater than that of a bubble column (NBNO). The $\mathrm{k}_{\mathrm{L}} \mathrm{a}$ in a baffled column was not affected in the presence of liquid oscillation (NBWO) as compared to a bubble column. The presence of baffles without liquid oscillation caused $\mathrm{CO}_{2}$ to flow only through the centre of column, making gas transfer near the walls more difficult. Under this condition, the $k_{t} a$ obtained was lower compared to that of a bubble column.

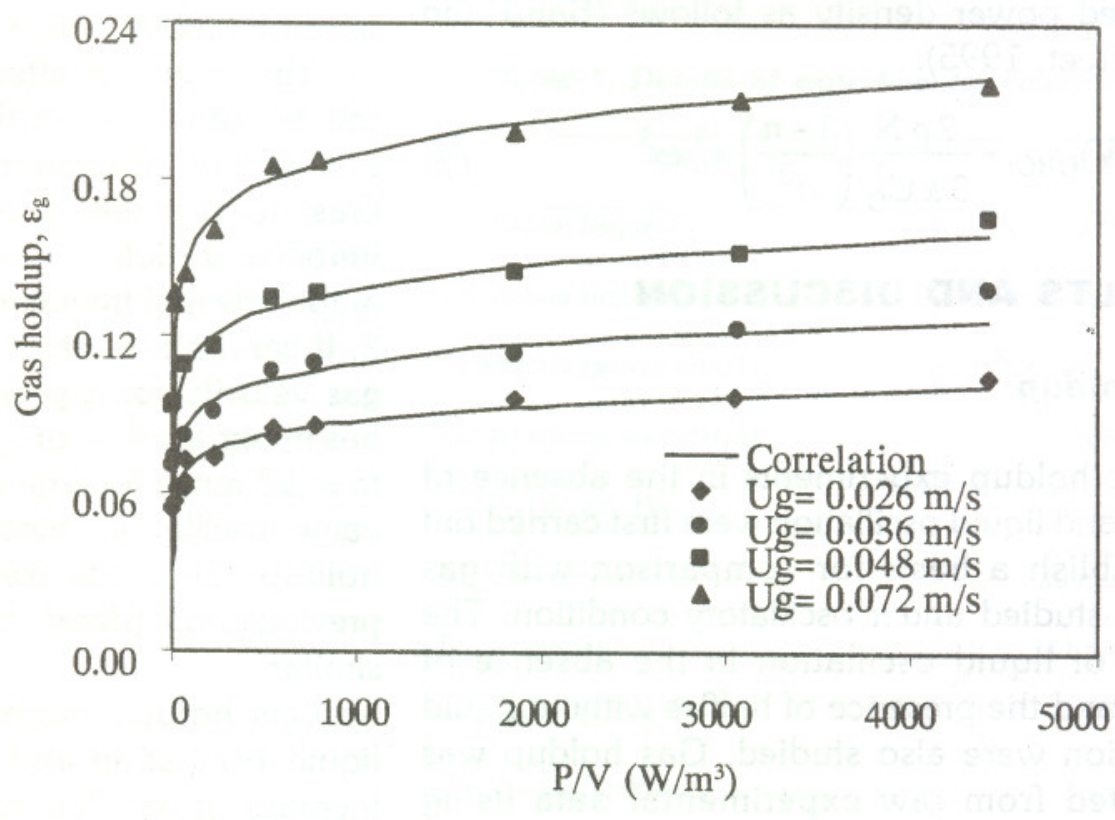

Figure 3. The $\varepsilon_{g}$ versus power consumption calculated using Equation (7) 


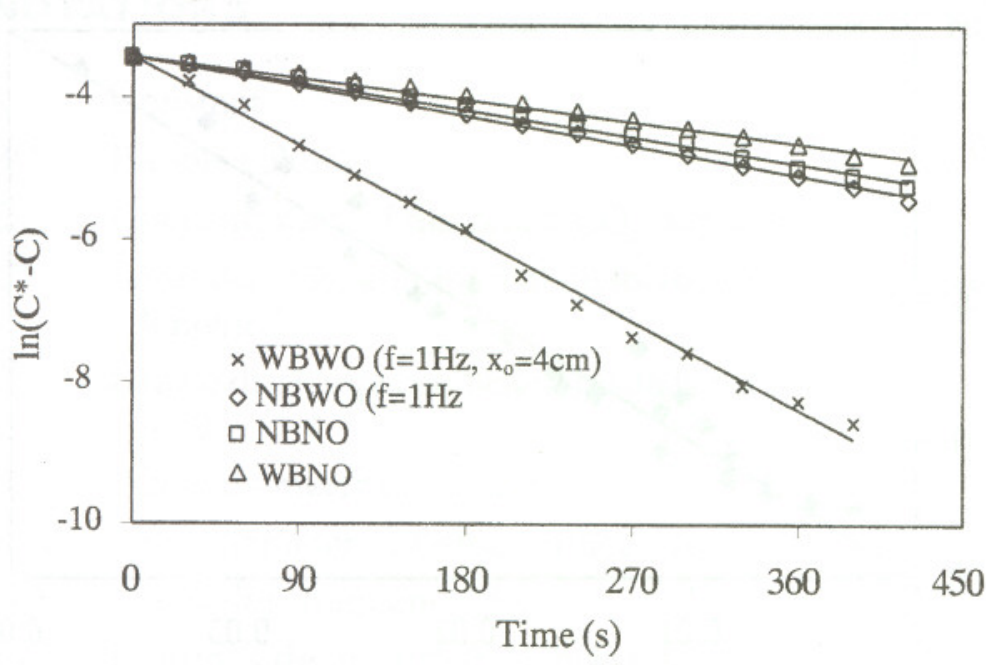

Figure 4. A log plot of the concentration versus time for various conditions at $U_{g}=0.026 \mathrm{~m} / \mathrm{s}$

Table 2. The values of $k_{L} a$ for Figure 4

\begin{tabular}{|l|c|}
\hline \multicolumn{1}{|c|}{ Conditions } & $\mathrm{k}_{\mathrm{L}} \mathrm{a}, 1 / \mathrm{s}$ \\
\hline With baffles, no oscillation (WBNO) & 0.0033 \\
No baffles, no oscillation (NBNO) & 0.0044 \\
No baffles, with oscillation (NBWO) & 0.0046 \\
With baffles, with oscillation (WBWO) & 0.0137 \\
\hline
\end{tabular}

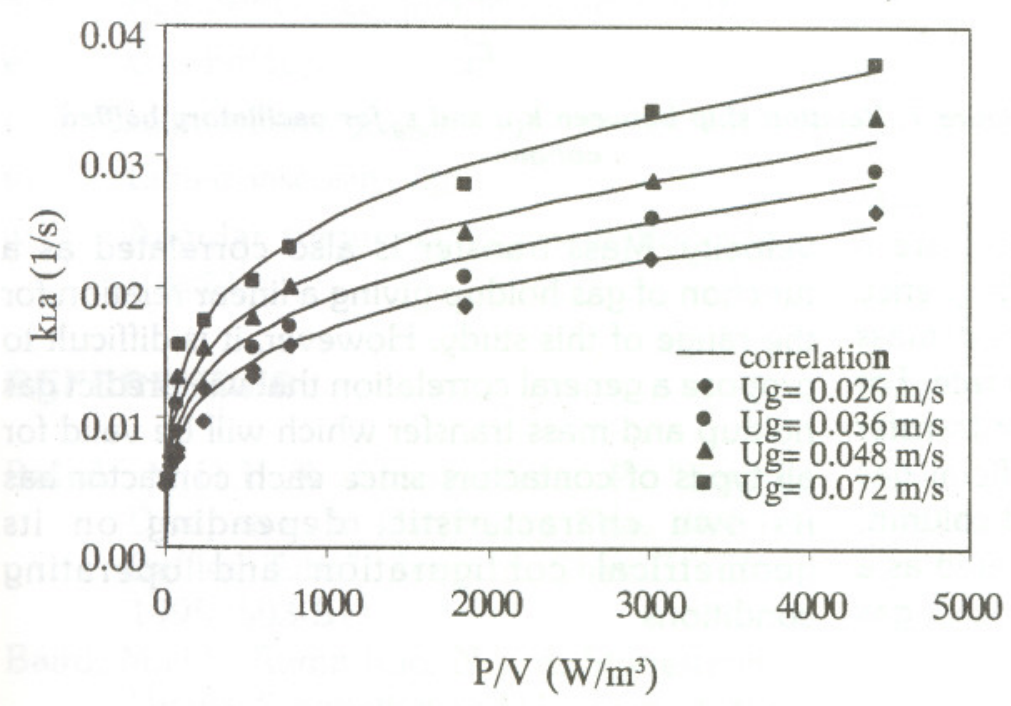

Figure 5. The $k_{L} a$ versus power consumption calculated from Equation (7)
The $\mathrm{k}_{\mathrm{L}} \mathrm{a}$ under oscillatory condition were plotted against power density in Figure 5 at a fixed superficial gas velocity. This figure shows that the $\mathrm{k}_{\mathrm{t}} \mathrm{a}$ increases with power density. At a higher power density, mixing becomes more intense, giving a higher degree of mass transfer. However, the degree of the increase in mass transfer was found to be less for higher power densities than for lower ones. This could suggest that a threshold in the uniformity of mixing in oscillatory baffled columns exists. Once the column reaches such a uniformity, further increase in power density would not have an impact on mass transfer

For the bubble column, the experimental data can be correlated to superficial gas velocity as follows (Deckwer et. al., 1974):

$$
\mathrm{k}_{\mathrm{L}} \mathrm{a}=\mathrm{a}_{4} \mathrm{U}_{\mathrm{g}}^{\mathrm{f}}
$$

The experimental values give $\mathrm{a}_{4}=$ 0.079 and $f=0.81$, which is in close agreement with results found in a related literature (Deckwer et. al., 1974). In the presence of orifice baffles in a column without oscillation, the values of $\mathrm{a}_{4}$ and f were reduced to 0.059 and 0.79 , respectively.

Linek et.al., (1987) derived a correlation between $\mathrm{k}_{\mathrm{L}} \mathrm{a}$ and power density for gas-sparger systems in agitated vessels in general, which was given as follows:

$$
\mathrm{k}_{\mathrm{L}} \mathrm{a}=\mathrm{a}_{5}(\mathrm{P} / \mathrm{V})_{\mathrm{ST}}^{\mathrm{m}} \mathrm{U}_{\mathrm{g}}^{\mathrm{n}}
$$

The present data were fitted with power density using Equation (7) to arrive at a general form as shown in Equation (12):

$$
\mathrm{k}_{\mathrm{L}} \mathrm{a}=0.012(\mathrm{P} / \mathrm{V})_{\mathrm{OBC}}^{0.26} \mathrm{U}_{\mathrm{g}}^{0.4}
$$

Figure 6 shows the experimental data plotted versus the values of $\mathrm{k}_{\mathrm{L}} \mathrm{a}$ calculated from the above correlation. 
Each data point in Figure 6 represents one experiment. The data show good agreement with the correlation.

Qualitatively, Figures 3 and 5 exhibit a similar trend, suggesting that it may be possible to correlate the $\mathrm{k}_{\mathrm{L}}$ a as a function of $e_{g}$. An effort to correlate the $\mathrm{k}_{\mathrm{L}} \mathrm{a}$ with $e_{\mathrm{g}}$ was made as illustrated in Figure 7. This Figure shows a plot of the $\mathrm{k}_{\mathrm{L}} \mathrm{a}$ against $e_{\mathrm{g}}$ for data obtained in the oscillatory baffled column. The values of the $\mathrm{k}_{\mathrm{t}} \mathrm{a}$ were found to be linearly proportional to gas holdup. Data in Figure 7 were fitted with a straight line with a slope of 0.17 .

\section{CONCLUSION}

The experimental results described in this paper show that gas holdup and mass transfer in semi-batch operations are significantly improved in an oscillatory baffled column compared to a bubble column. Liquid oscillation alone does not have an effect on gas holdup and mass transfer, while orifice baffles alone lower gas holdup and mass transfer within the range used. When orifice baffles are inserted into the column, gas

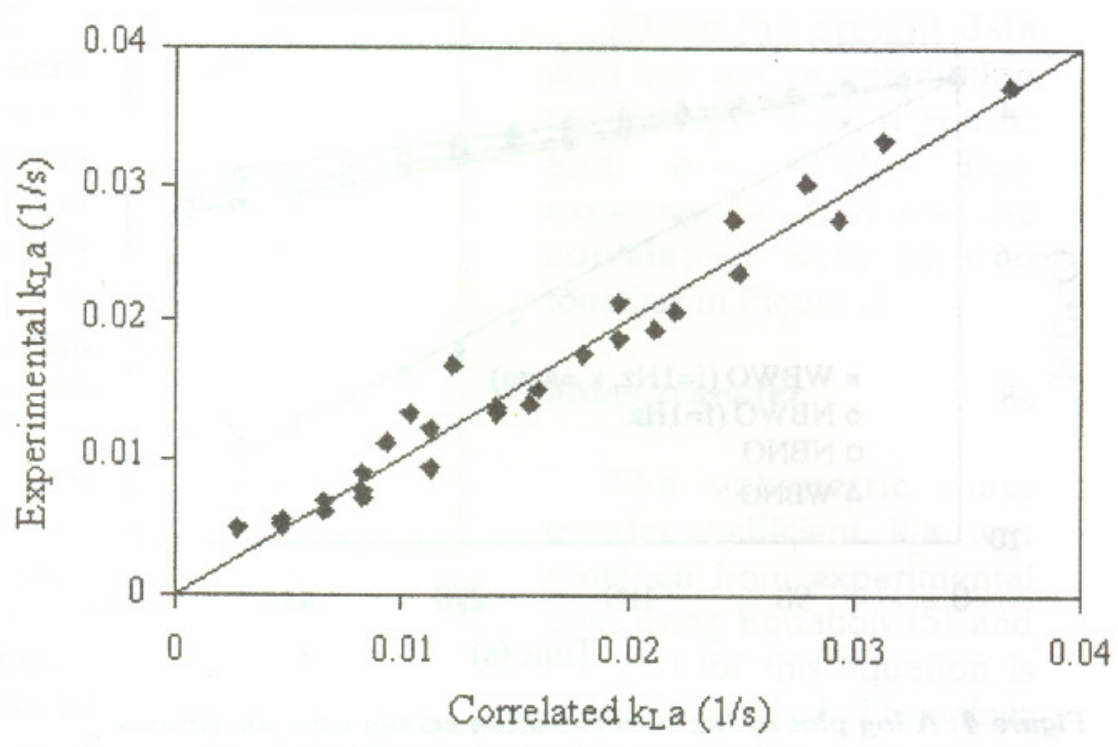

Figure 6. Experimental $k_{L} a$ data versus calculated data using correlation of Equation (13)

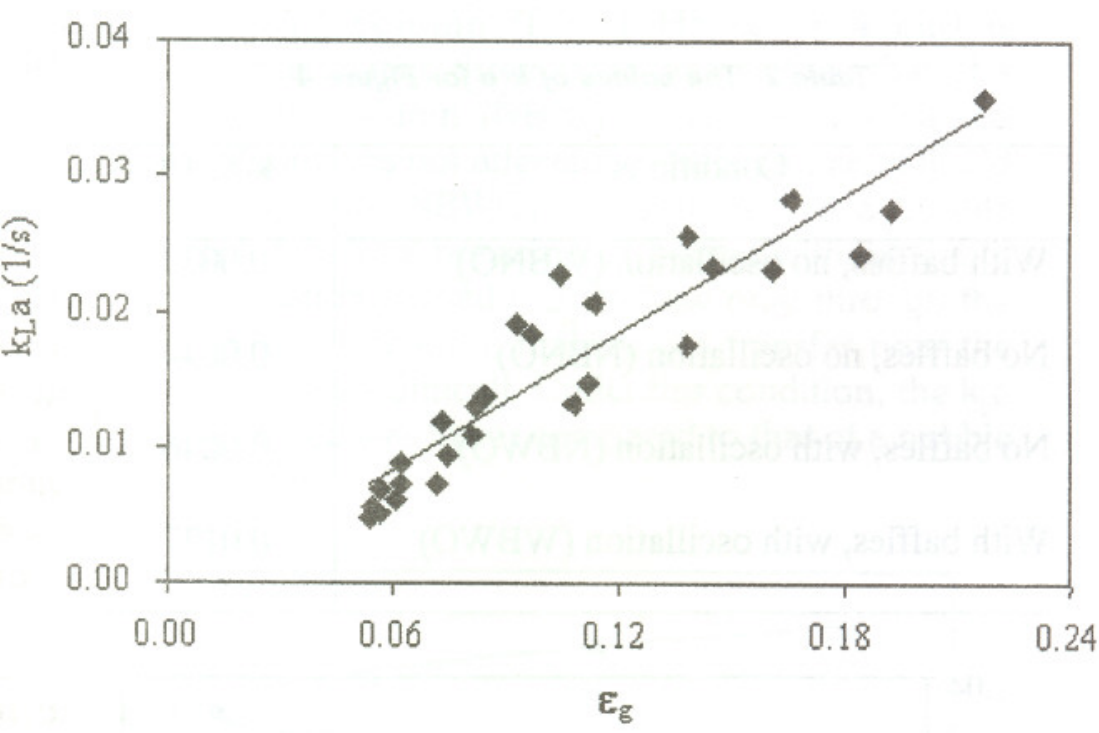

Figure 7. Relation ship between $k_{L} a$ and $\varepsilon_{g}$ for oscillatory baffled column

holdup and mass transfer improvements are a strong function of the amplitude and frequency of oscillation. Moreover, gas holdup and mass transfer are also increased with gas flow rate. For the bubble column, gas holdup and mass transfer are correlated as a function of superficial gas velocity, while for the oscillatory baffled column, gas holdup and mass transfer are correlated as a function of power density and superficial gas velocity. Mass transfer is also correlated as a function of gas holdup giving a linear relation for the range of this study. However, it is difficult to propose a general correlation that will predict gas holdup and mass transfer which will be valid for all types of contactors since each contactor has its own characteristic, depending on its geometrical configuration and operating conditions. 


\section{NOTATIONS}

a Constant

BC Bubble column

C Concentration of dissolved $\mathrm{CO}_{2}, \mathrm{kmol} / \mathrm{m}^{3}$

$\mathrm{C}^{*} \quad$ Saturated concentration of dissolved $\mathrm{CO}_{2}$, $\mathrm{kmol} / \mathrm{m}^{3}$

$C_{D} \quad$ Orifice discharge coefficient (usually taken as 0.7 )

D Inside diameter of column, $m$

$\mathrm{D}$. Inner diameter of baffle (orifice), $\mathrm{m}$

f Oscillation frequency, $\mathrm{Hz}$

$\mathrm{k}_{\mathrm{L}} \mathrm{a} \quad$ Liquid-side volumetric mass transfer coefficient, $1 / \mathrm{s}$

$\mathrm{N} \quad$ Number of baffles per unit length, $1 / \mathrm{m}$

OBC Oscillatory baffled column

$\mathrm{P} / \mathrm{V} \quad$ Power density, $\mathrm{W} / \mathrm{m}^{3}$

$Q_{\mathrm{g}} \quad$ Volumetric gas flow rate, $\mathrm{m}^{3} / \mathrm{s}$

Re. Oscillatory Reynolds number

St Strouhal number

ST Stirred tank/vessel

$\mathrm{t}$ Time, $\mathrm{s}$

$\mathrm{U}_{\mathrm{g}} \quad$ Superficial gas velocity, $\mathrm{m} / \mathrm{s}$

$V_{1} \quad$ Liquid volume of the column, $\mathrm{m}^{3}$

$\mathrm{V}_{\mathrm{g}} \quad$ Gas volume of the column, $\mathrm{m}^{3}$

$x_{0} \quad$ Center to peak amplitude of oscillation or haft of stroke length, $m$

a Ratio of orifice area to column area

$e_{\mathrm{g}} \quad$ Gas holdup

r Liquid density, $\mathrm{kg} / \mathrm{m}^{3}$

$\mathrm{m} \quad$ Liquid viscosity, $\mathrm{kg} /(\mathrm{m} \cdot \mathrm{s})$

w Angular frequency of oscillation (2pf), $\mathrm{rad} / \mathrm{s}$

\section{REFERENCES}

Baird, M.H.I. \& Stonestreet, P. "Energy Dissipation in Oscillatory Flow Within a Baffled Tube". Trans. I. ChemE., 73(A), 1995, 503-511.

Baird, M.H.I., Rama Rao, N.V. \& Stonestreet, P. "Power Dissipation and Holup in a Gassed Reciprocating Baffle-Plate Column". Trans. I. ChemE., 74(A), 1996, 463-470.
Bouaifi, M., Hebrard, G., Bastoul, D. \& Roustan, M. "A Comparative Study of Gas Holdup, Bubble Size, Interfacial Area and Mass Transfer Coefficients in Stirred Gas-Liquid Reactors and Bubble Columns". Chem. Eng. Processing, 40(2), 2001, 97-111.

Brunold, C.R., Hunn, J.C.B., Mackley, M.R. \& Thomson, J.W. "Experimental Observations on Flow Patterns and Energy Looses for Oscillatory Flow in Ducts Containing Sharp Edges". Chem. Eng. Sci., 44(5), 1989, 1227-1244.

Deckwer, W.D., Burkhart, R. \& Zoll, G. "Mixing and Mass Transfer in tall bubble columns". Chem. Eng. Sci., 29(11), 1974, 2177. 2188.

Dickens, A.W., Mackley, M.R. \& William, H.R. "Experimental Residence Time Distribution Measurements for Unsteady Flow in Baffled Tubes". Chem. Eng. Sci., 44(7), 1989, 1471-1479.

Jealous, A.C. \& Johnson, H.F. "Power Requirements for Pulse Generation in Pulse Column". Ind. Eng. Chem., 47(6), 1955, 1159-1166.

Hewgill, M.R., Mackley, M.R., Pandit, A.B. \& Pannu, S.S. "Enhancement of Gas-Liquid Mass Transfer Using Oscillatory Flow in Baffled Tubes". Chem. Eng. Sci., 48(4), 1993, 799-803.

Linek, V., Benes, P. \& Vacek, V. "A Critical Review and Experimental Verification of the Correct Used of the Dynamic Method for the Determination of Oxygen Transfer in Aerated Agitated Vessels to Water, Electrolyte Solutions and Viscous Fluids". Chem. Eng. J., 34, 1987, 11-34.

Mackay, M.E.,. Mackley, M.R. \& Wang, Y. "Oscillatory Flow within Tubes Containing Wall or Central Baffles". Trans. I. ChemE., 71(A), 1991, 649-656.

Mackley, M.R. "Using Oscillatory Flow to Improve Performance". The Chemical Engineer. February, 1987, 18-20.

Mackley, M.R. "Process Innovation Using Oscillatory Flow within Baffled Tubes". Trans. I. ChemE., 69(A), 1991, 197-199.

$\mathrm{Ni}, \mathrm{X}$. \& Gough, P. "On the Discussion of Dimensionless Groups Governing Oscillatory Flow in a Baffled Tube". Chem. Eng. Sci., 52(18), 1997, 3209-3212. 
Robert, E.P.L. "The Simulation of Chaotic Advection for Application to Process Engineering". Trans. I. ChemE., 69 (A), 1991, 208-210.

Shah, Y.T., Deckwer, W.D., Kelkar, B.G. \& Godbole, S.P. "Design Parameters Estimations for Bubble Column Reactors. A.I.Ch.E.J., 28(3), 1982, 353-379. 